\title{
Sulphated and unsulphated bile acids in serum, bile, and urine of patients with cholestasis ${ }^{1}$
}

\author{
G. P. VAN BERGE HENEGOUWEN ${ }^{2}, K-H$. BRANDT, H. EYSSEN, AND \\ G. PARMENTIER
}

From the Department of Internal Medicine, Municipal Hospital, Arnhem, The Netherlands; Rega Institute, Louvain, Belgium

SUMMARY Samples of serum, bile, and urine were collected simultaneously from patients with cholestasis of varying aetiology and from patients with cirrhosis; their bile acid composition was determined by gas/liquid chromatography and mass spectrometry In cholestasis, the patterns in all three body fluids differed consistently and strikingly. In serum, cholic acid was the major bile acid and most bile acids (>93\%) were unsulphated, whereas, in urine, chenodeoxycholic was the major bile acid, and the majority of bile acids $(>60 \%)$ were sulphated. Secondary bile acids were virtually absent in bile, serum, and urine. The total amount of bile acids excreted for 24 hours correlated highly with the concentration of serum bile acids; in patients with complete obstruction, urinary excretion averaged $71.6 \mathrm{mg} / 24 \mathrm{~h}$. In cirrhotic patients, serum bile acids were less raised, and chenodeoxycholic acid was the predominant acid. In healthy controls, serum bile acids were consistently richer in chenodeoxycholic acid than biliary bile acids, and no bile acids were present in urine. No unusual monohydroxy bile acids were present in patients with primary biliary cirrhosis, but, in several patients, there was a considerable amount of hyocholic acid present in the urinary bile acids. The analyses of individual bile acids in serum and urine did not appear to provide helpful information in the differential diagnosis of cholestasis. Thus, in cholestasis, conjugation of chenodeoxycholic acid with sulphate becomes a major biochemical pathway, urine becomes a major route of bile acid excretion, and abnormal bile acids are formed.

In cholestasis the enterohepatic circulation of bile acids is interrupted and retention of bile acids in the liver occurs with a rise in serum bile acid levels. Renal excretion of bile acids becomes a significant route of elimination (Gregg, 1967) and sulphation of bile acids seems to play an important role in the rate of renal excretion (Palmer, 1967; Admirand et al.,

\footnotetext{
1 Part of this work was presented at the Third Bile Acid Meeting, 13-15 June 1974, Freiburg, West Germany, and at the 76th Annual Meeting of the American Gastroenterological Association, 17-22 May 1975, San Antonio, Texas, USA, and published in abstract form (Gastroenterology, 68: 1005, 1975).
}

${ }^{2}$ Present addresss and for reprints: Nijmegen University School of Medicine, Department of Internal Medicine, Division of Gastroenterology, St. Radboud Hospital, Nijmegen, Netherlands.

Received for publication 28 June 1976
1972; Stiehl, 1974). Older studies using methods of low precision and sensitivity suggested that cholic acid became the major bile acid in biliary obstruction (Rudman and Kendall, 1957; Carey, 1958), a finding generally confirmed by more recent studies (Makino et al., 1969; Murphy et al., 1972; Greim et al., 1972). More recently, unsaturated monohydroxy bile acids have been detected in urine and serum of cholestatic patients (Makino et al., 1971; Back, 1973).

The aim of our study was to define the bile acid pattern of simultaneously obtained serum, bile, and urine samples in patients with cholestasis in order to gain insight into the changes occurring in bile acid metabolism in this condition. We report here such analyses in a well-defined group of patients, as well as similar analyses in samples from patients with cirrhosis and healthy control subjects. After this work had been completed, analysis of serum and urine bile 
acids in patients with cirrhosis was reported by Stiehl et al. (1975). Makino et al. (1975) also reported results of bile acid analyses in samples of serum, urine, and bile of patients with cirrhosis.

\section{Methods}

\section{PATIENTS}

Thirty-two patients with cholestasis of varying aetiology were studied as well as 18 patients with cirrhosis (Table 1) and healthy control subjects. Diagnosis was established by liver biopsy. The diagnosis of total obstruction of the biliary tract was made before laparotomy and cholangiography on the basis of negative urinary and faecal urobilin excretion and confirmed at laparotomy. All patients with complete obstructions were in a steady-state condition when samples were collected, as repeated liver function tests-for example, bilirubin, SGOT, SGPT, alkaline phosphatase, 5'-nucleotidase, cholesterol, and protein electrophoresis-revealed no significant changes over a two week period.

Pruritus was graded on a scale from 1 to 4 by predefined criteria.

\section{Collection of samples}

Serum samples were collected during the fasting state. In 26 (13 cirrhosis and 13 primary biliary cirrhosis) patients and in 15 control subjects, serum and bile samples were collected simultaneously. Bile rich duodenal fluid was obtained, under standardised conditions, five to 15 minutes after cholecystokinin (Cecekin, Vitrum, Stockholm) stimulation using a double lumen Dreiling tube. Samples were stored at $-20^{\circ} \mathrm{C}$

Urine analyses were carried out on 24-hour collections from 23 patients with cholestasis and six normal controls; serum of these patients was obtained in the fasting state on the same day that the 24-hour urine collection was done. All patients had a normal renal function, as assessed by serum creatinine. During collection urine was stored at $4^{\circ} \mathrm{C}$ and thereafter at $-20^{\circ} \mathrm{C}$.

\section{Bile acid analyses}

Major steps in isolation and preparation of bile acids from serum and urine are summarised in Fig. 1. Bile acids are referred to by their trivial names only; for systematic nomenclature, see Hofmann and Mosbach (1964). Since hydrolysis and solvolysis steps were included in the analyses, the data provide no information on the degree or mode of conjugation.

Serum and bile Unsulphated bile acids were analysed as described (van Berge Henegouwen et al.,

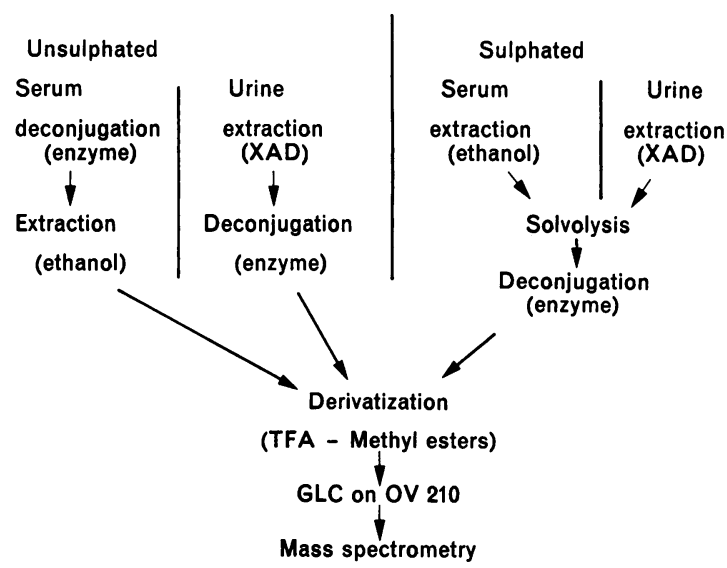

Fig. 1 Procedure for analyses of unsulphated (left) or sulphated (right) bile acids.

Table 1 Clinical data of subjects studied

\begin{tabular}{|c|c|c|c|}
\hline Number & Diagnosis & Aetiology and pathology & Reference for diagnostic criteria \\
\hline$\overline{18}$ & Cirrhosis (needle biopsy) & $\begin{array}{l}\text { Cryptogenic (5) } \\
\text { Alcoholic (5) } \\
\text { Chronic aggressive } \\
\text { hepatitis (3) } \\
\text { Post hepatitic (4) } \\
\text { Haemochromatosis (1) }\end{array}$ & Scheuer (1973) \\
\hline 19 & $\begin{array}{l}\text { Primary biliary cirrhosis } \\
\text { (needle or wedge biopsy) }\end{array}$ & $\begin{array}{l}\text { Stage } \\
\text { I (4) } \\
\text { II (5) } \\
\text { III (7) } \\
\text { IV (3) }\end{array}$ & Popper and Schaffner (1970) \\
\hline 13 & $\begin{array}{l}\text { Complete extrahepatic } \\
\text { obstruction (laparotomy) }\end{array}$ & $\begin{array}{l}\text { Carcinoma } \\
\text { Bile duct (6) } \\
\text { Pancreatic (6) } \\
\text { Gastric, with invasive growth (1) }\end{array}$ & \\
\hline 15 & Healthy controls & & \\
\hline
\end{tabular}


1974). In preliminary studies of 10 serum and 10 bile samples, solvolysis (Palmer and Bolt, 1971) was added to the isolation procedure in order to detect sulphated bile acids. As these studies indicated that the proportion of bile acids present as sulphates in serum and bile was quite low, the solvolysis step was not included routinely in the analysis of bile acids in serum or bile. Recovery for conjugated reference bile acids was satisfactory ( 84.5 to $96.3 \%$ ), and good separation between the individual bile acids-cholic acid, chenodeoxycholic acid, deoxycholic acid, and lithocholic acid-and the internal standard 7ketodeoxycholic acid was achieved by gas/liquid chromatography (GLC) (van Berge Henegouwen et al., 1974). Determinations of conjugated serum cholic and chenodeoxycholic acid were also performed by radioimmunoassay (Simmonds et al., 1973; and Schalm et al., 1975), and the values correlated well with our GLC method. The correlation coefficient of serum cholic acid was 0.99 with a slope of 0.84 (concentration range 7.0 to $456.0 \mu \mathrm{mol} / \mathrm{l}$ ) and for serum chenodeoxycholic acid 1.00 with a slope of 1.20 (concentration range 0.8 to $235.2 \mu \mathrm{mol} / \mathrm{l}$ ).

Urine Sulphated and unsulphated bile acids were isolated from urine with Amberlite- $\mathrm{XAD}_{2}$ obtained from Rohm and Haas, Co., Philadelphia, PA, USA. Instead of adsorption by passage over a column (Makino and Sjövall, 1972), adsorption of bile acids was achieved by a batch procedure. One gram of the $\mathrm{XAD}_{2}$ was added to each sample of $5 \mathrm{ml}$ urine with $5 \mathrm{ml} 0 \cdot 2 \mathrm{NaOH}$. After shaking for 60 minutes, the resin was centrifuged and washed. Bile acids were eluted from the resin with methanol. Each urine sample was processed with and without solvolysis to separate sulphated and unsulphated bile acids. Solvolysis was done to hydrolyse bile acid sulphates. After evaporation until dryness the residue was therefore dissolved in acetone and ethanol $(9: 1$, with 1 drop of $6 \mathrm{~N} \mathrm{HCl}$ ). This mixture was stored for one to three days at room temperature and then evaporated until dryness. After refluxing for two hours with $2 \%$ methanolic $\mathrm{KOH}$, the solution was neutralised using Dowex 50W-X 4 , filtered with methanol and evaporated. The residue was dissolved in water; enzymatic hydrolysis and preparation of trifluoroacetate methyl ester derivatives of bile acids for GLC were carried out as described (van Berge Henegouwen et al., 1974). Recoveries for conjugated bile acids in urine carried through the entire procedure with solvolysis were 80.0 to $84.5 \%$ and 84.0 to $90.0 \%$ for the entire procedure without solvolysis (van Berge Henegouwen, 1974). Recoveries of bile acid sulphates could not be calculated because no suitable standards were available. In urine of normal controls, only trace amounts of bile acids were detect- able (less than $0.2 \mathrm{mg} / \mathrm{l}$ ) and solvolysis did not increase the amount of bile acids.

Mass spectrometry As several urine samples of patients with cholestasis showed unusual peaks, combined gas/liquid chromatography-mass spectrometric studies were carried out. The identity of lithocholic acid, $3 \beta$-hydroxy-5-cholen-24-oic acid, ursodeoxycholic acid, and hyocholic acid was confirmed using combined gas/liquid chromatography-mass spectrometry (standards of bile acids tested were obtained from Steroloids Inc. (Pawling, NY). For the identification studies not only bile acid methyl ester acetates, but also trimethylsilyl ether derivatives were prepared. They were separated on columns packed with $3 \%$ OV-1, $3 \%$ OV-17,; or $3 \%$ Hi-Eff 8BP. Mass spectrometry was carried out using a combined Pye (Series 104) chromatography-AEI-MS mass spectrometer. Helium was used as carrier gas.

As the presence of hyocholic acid in human urine was unexpected, supplementary work to prove the structure was carried out. Acetic acid is lost very easily from the acetoxy derivatives of bile acids in the mass spectrometer at high temperature, but trimethylsilyl ether derivatives, which can be chromatographed at lower temperatures, are less well removed on most stationary phases by GLC. We, therefore, isolated the compounds in the form of their methyl esters by preparative thin-layer chromatography using chloroform-acetone-methanol (70:25: $5)$. Methyl esters of reference bile acids were cochromatographed on the left and on the right side of the plate. The silica gel band corresponding to the hyocholic acid region was scraped off and eluted with chloroform:methanol $(1: 1, \mathrm{v} / \mathrm{v})$. The eluate was divided into aliquots for GLC and mass spectrometry, and the solvent was evaporated. The mass spectra of the methyl esters and of the trimethylsilyl ether were recorded and shown to be identical with those of the derivative of the authentic hyocholic acid and to differ from the mass spectra of its $7 \beta$ epimers, $\omega$ - and $\beta$-muricholic acid. As only trace amounts of unusual peaks showed up in serum and bile samples, no additional mass spectrometric analyses were performed for serum or bile.

Statistical analyses Unless otherwise mentioned, statistical analyses were done using the paired $t$ test; correlation coefficients $(r)$ were calculated by the rank correlation test of Spearman.

\section{Results}

CHOLESTASIS: SERUM BILE ACIDS

Total serum bile acids were raised in every subject. More cholic acid than chenodeoxycholic acid was present in most patients, and the proportion of 
cholic was greatest in patients with the highest levels (Fig. 2). The proportion present as deoxycholic and lithocholic was extremely low. Analyses before and after solvolysis indicated that sulphates comprised less than $7 \%$ of the serum bile acids and consisted mainly of sulphated chenodeoxycholic acid.

\section{CHOLESTASIS: URINE BILE ACIDS}

Urinary bile acids were consistently raised, and the daily excretions correlated highly $(r=0.85)$ with serum concentrations. In the 23 patients studied, urinary bile acids ranged from 3.1 to $79.8 \mathrm{mg} / 24 \mathrm{~h}$ with mean $( \pm S D)$ of $31.4 \mathrm{mg} / 24 \mathrm{~h}( \pm 21.0)$. In these 23 patients, serum bile acids ranged from 9.0 to $218.4 \mu \mathrm{mol} / 1$ with a mean $( \pm \mathrm{SD})$ of $120.5 \mu \mathrm{mol} / 1$ $( \pm 41 \cdot 1)$. In patients with complete obstruction, the average daily excretion was $71.6 \mathrm{mg}$.

The pattern of urine bile acids differed markedly from that of serum bile acids in that sulphated chenodeoxycholic acid was the major bile acid present in urine (Figs. 3 and 4). Clearances of sulphated and unsulphated bile acids were calculated in 10 patients from the 24-hour urine excretions and serum bile acid concentrations (Fig. 5). The renal clearance of sulphated bile acids was 10 to 100 times greater than that of unsulphated bile acids. This calculation assumes that all sulphated bile acids in urine originated from plasma. If there is sulphation and secretion into urine of bile acids by the renal tubule, the calculated values are an overestimate.

\section{CHOLESTASIS: BILIARY BILE ACIDS}

Mean biliary bile acid composition and bile acid concentration for the different diseases is given in Table 2 . In patients with primary biliary cirrhosis, the proportion of cholic acid was increased. No abnormal bileacids were detected in the bile of patients with primary biliary cirrhosis, and the total lithocholic concentrations were always below $3 \%$ of the total biliary bile acid concentration. The lithocholic peak increased after solvolysis, indicating that a major part was present as a sulphate ( $>60 \%$ ).

In 13 patients with primary biliary cirrhosis, bile samples and fasting serum samples were obtained simultaneously. In all but one patient, serum contained more chenodeoxycholic acid than bile.

\section{CHOLESTASIS: NOVEL BILE ACIDS}

Six of seven urine samples contained considerable amounts ( 2.5 to $21.3 \mu \mathrm{mol} / 24 \mathrm{~h})$ of a bile acid having the retention time on gas/liquid chromatography of hyocholic acid. By mass spectrometry, the fragmen-

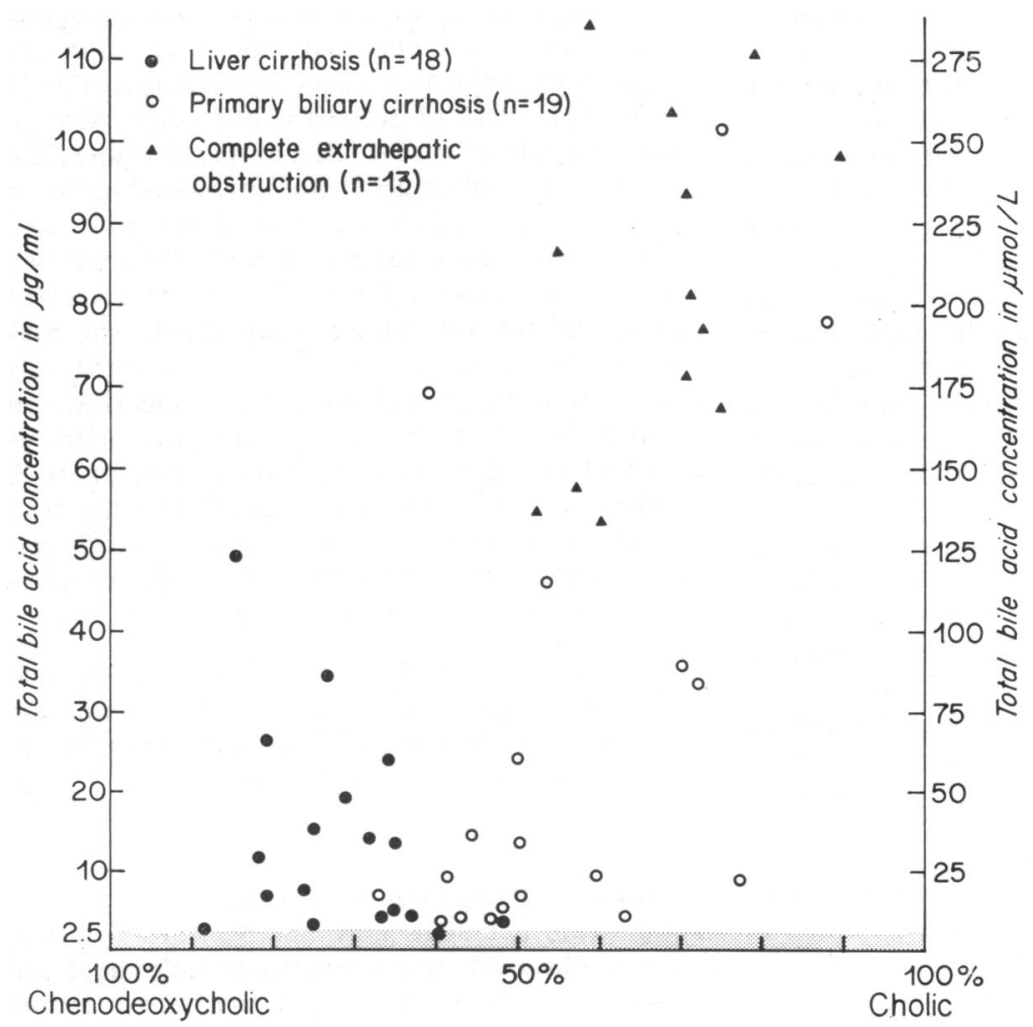

Fig. 2 Serum bile acid composition (abscissa) and concentration (ordinate) in patients with liver cirrhosis $(\bigcirc)$, patients with primary biliary cirrhosis $(\mathrm{O})$, and patients with complete extrahepatic obstruction ( $\Delta)$. Since lithocholic and deoxycholic acids compose less than $5 \%$ of total bile acids, only cholic acid and chenodeoxycholic acid concentrations are shown. Total bile acid concentration in healthy subjects was less than $6.3 \mu M(2.5 \mu \mathrm{g} / \mathrm{ml})$, and the upper limits of normal values are indicated by the hatched area. 


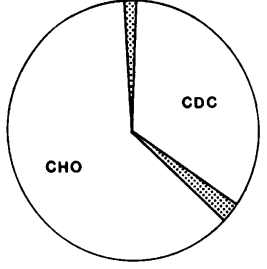

Serum

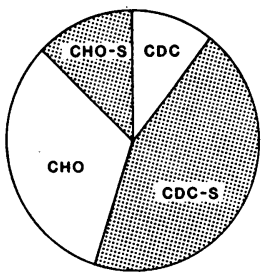

Urine
Fig. 3 Bile acid composition of serum and urine $(\%$, normalised to $100 \%)$ from 23 patients with cholestasis shown using circular coordinates. Only cholic and chenodeoxycholic acids are shown, as other bile acids constituted less than $5 \%$ of the total bile acids in any sample. Abbreviations; cholic acid ( $\mathrm{CHO})$, sulphated cholic acid (CHO-S), chenodeoxycholic acid (CDC), and sulphated chenodeoxycholic acid $(C D C-S)$.

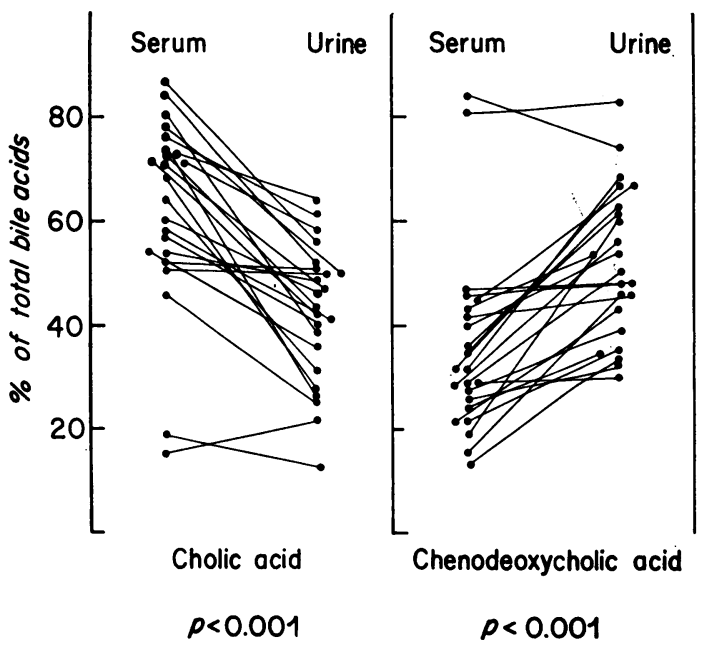

Fig. 4 Bile acid composition of serum samples and 24-hour urine collections in 23 patients with cholestasis. The serum sample was obtained on the day of the urine collection. The percentage represents the sum of sulphated and unsulphated species.

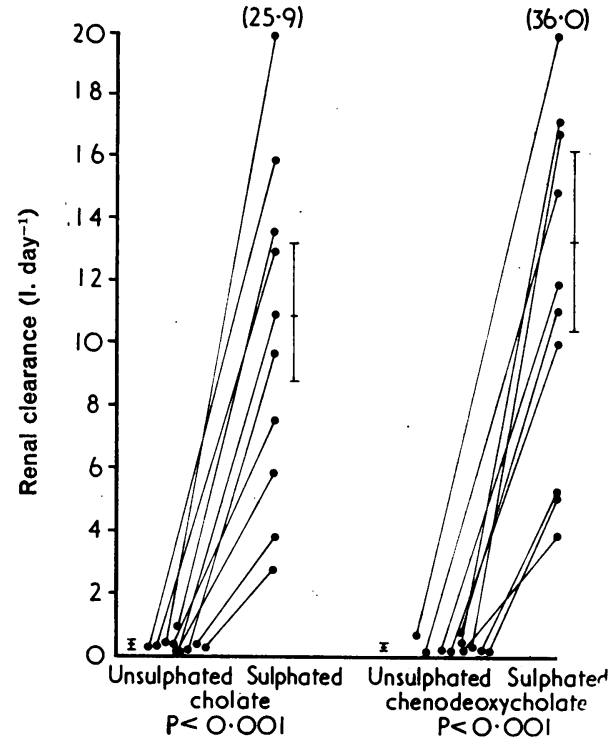

Fig. 5 Renal clearances for sulphated and unsulphated bile acids for 10 patients. The mean and SEM are shown. Renal clearance on the ordinate is expressed in l/day.

tation pattern of the trimethylsilyl ether was consistent with that of the $7 \alpha$ epimer of a 3,6,7-trihydroxy- $5 \beta$-cholanoic acid. A base peak was found at $\mathrm{m} / \mathrm{e}$ 458. In contrast, the $7 \beta$ epimers, $\omega$ - and $\beta$ muricholic acid gave a base peak at $\mathrm{m} / \mathrm{e} 285$, which is the result of fission between carbon atoms 6 and 7. The second prominent peak was present at $\mathrm{m} / \mathrm{e} 369$, which is typical for vicinal trimethylsiloxy groups. No peaks were observed at $\mathrm{m} / \mathrm{e} 343$ and 253 , which are conspicuous in the spectrum of the trimethylsilyl derivatives of cholic acid. Trace amounts of an unsaturated monohydroxy bile acid ( $3 \beta$-hydroxy-5cholen-24-oic acid) were found in three patients, and trace amounts of ursodeoxycholic acid were found in two patients. The structure of these bile acids was also confirmed by mass spectrometry.

Table 2 Biliary bile acid composition and concentration in duodenal bile samples obtained after CCK stimulation

\begin{tabular}{|c|c|c|c|c|}
\hline \multirow[t]{2}{*}{ Group } & \multicolumn{4}{|l|}{ Acid } \\
\hline & Cholic & Chenodeoxycholic & Deoxycholic & Lithocholic \\
\hline $\begin{array}{l}\text { I. Mean composition }(\% \pm S E M) \\
\text { 1. Primary biliary cirrhosis }(N=13) \\
\text { 2. Liver cirrhosis }(N=13) \\
\text { 3. Normal controls }(N=15)\end{array}$ & $\begin{array}{l}65 \cdot 0 *(18 \cdot 7) \\
43 \cdot 0(15 \cdot 1) \\
42 \cdot 0(4 \cdot 9)\end{array}$ & $\begin{array}{l}32 \cdot 5 \dagger(9 \cdot 4) \\
44 \cdot 6(9 \cdot 9) \\
44 \cdot 5 \quad(3 \cdot 7)\end{array}$ & $\begin{array}{c}2 \cdot 4^{*}(0 \cdot 6) \\
9 \cdot 8(2 \cdot 5) \\
11 \cdot 4 \quad(2 \cdot 0)\end{array}$ & $\begin{array}{l}0 \cdot 1 *(0 \cdot 03) \\
2 \cdot 6(0 \cdot 8) \\
2 \cdot 1 \quad(0 \cdot 2)\end{array}$ \\
\hline $\begin{array}{l}\text { II. Mean concentration }(\mu \mathrm{mol} / 1 \pm \mathrm{SEM}) \\
\text { 1. Liver cirrhosis }(\mathrm{N}=13) \\
\text { 2. Normal controls }(\mathrm{N}=15)\end{array}$ & $\begin{array}{c}6 \cdot 15^{*}(2 \cdot 45) \\
32 \cdot 28(4 \cdot 18)\end{array}$ & $\begin{array}{r}6 \cdot 35^{*}(1 \cdot 43) \\
33 \cdot 28 \quad(3 \cdot 25)\end{array}$ & $\begin{array}{l}1.40 *(0.35) \\
7 \cdot 30(1 \cdot 25)\end{array}$ & $\begin{array}{l}0 \cdot 33 *(0 \cdot 13) \\
1 \cdot 50(0 \cdot 15)\end{array}$ \\
\hline
\end{tabular}

*Significantly different from normal $(P<0.01)$ (Wilcoxon's rank sum test).

†Significantly different from normal $(P<0.05)$ (Wilcoxon's rank sum test). 


\section{CIRRHOSIS}

Total serum bile acids were raised in most patients, but in contrast with cholestasis, the major serum bile acid was chenodeoxycholic acid (Fig. 2). Urinary bile acids were increased, and as in the patients with cholestasis, the total bile acid excretion correlated highly with the total serum concentration. The major urinary bile acid was chenodeoxycholic acid, and the majority of this was preseni as the sulphate. Indeed, most of the sulphated bile acid fraction of urine was composed of chenodeoxycholic acid. The biliary bile acid pattern was similar to that of the healthy controls (Table 2). Cirrhotic patients tended to contain less deoxycholic acid in biliary bile acids than healthy controls, but the proportion was identical in serum and bile. As in the patients with cholestasis, the serum contained more chenodeoxycholic acid than bile (Fig. 6). Bile from cirrhotic patients was much more dilute than from healthy controls (Table 2). This has been described previously by Turnberg and Grahame (1970).

\section{HEALTHY CONTROL SUBJECTS}

Values for total fasting serum bile acids in healthy control subjects were less than $6 \cdot 3 \mu \mathrm{mol} / 1$. Serum cholic acid levels varied between 0.5 and $1.8 \mu \mathrm{mol} / \mathrm{l}$, and serum chenodeoxycholic acid levels between 0.7 and $3.5 \mu \mathrm{mol} / \mathrm{l}$. These values are in agreement with other reports (Sandberg et al., 1965; Makino et al., 1969). Serum bile acids contained more chenodeoxycholic acid than the biliary bile acids (Fig.7). No bile acids were detected in the urine of the healthy control subjects.

\section{CLINICAL CORRELATION}

The score of pruritus correlated highly with total serum bile acids $(r=0.78)$. There was an equally high correlation between the level of the major serum bile acid, cholic acid, and pruritus $(r=0.81)$.

In patients with primary biliary cirrhosis, there was no significant relationship between the pattern of serum bile acids and the stage of the disease, although the relative concentration of cholate was higher in the second and third stage of the disease. In the patients with complete extrahepatic obstruction there was no correlation between serum bilirubin and total bile acids or between total bile acids and alkaline phosphatase. In patients without complete extrahepatic obstruction, there was good correlation between serum bilirubin and total bile acids $(r=$

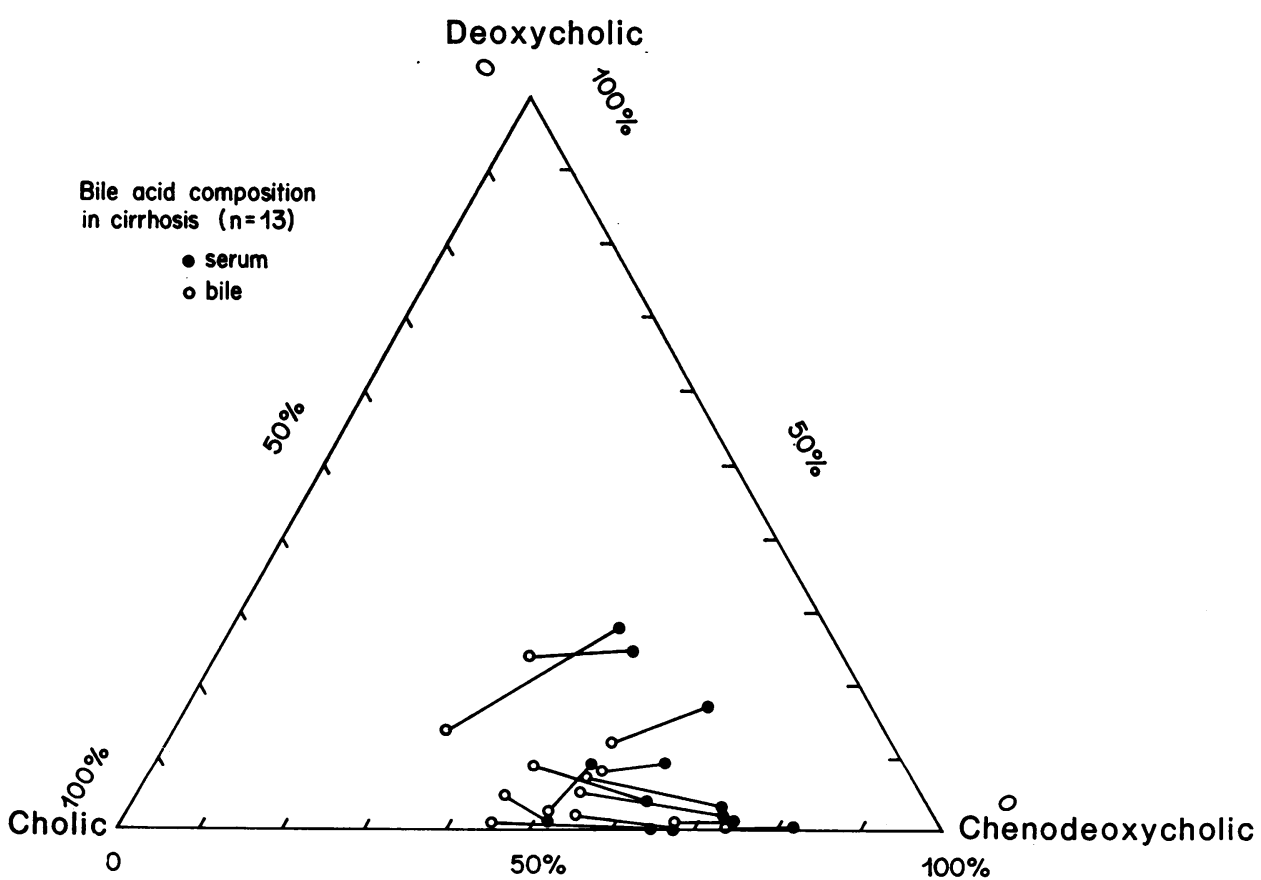

Fig. 6 Bile acid composition of samples of fasting-state serum and bile (obtained by CCK stimulation) from patients with cirrhosis; the data are plotted using triangular coordinates and with the assumption that total bile acids are composed solely of cholic, chenodeoxycholic, and deoxycholic acids. Lines connect samples from one patient. The greater proportion of chenodeoxycholic acid in the serum sample is statistically significant. 


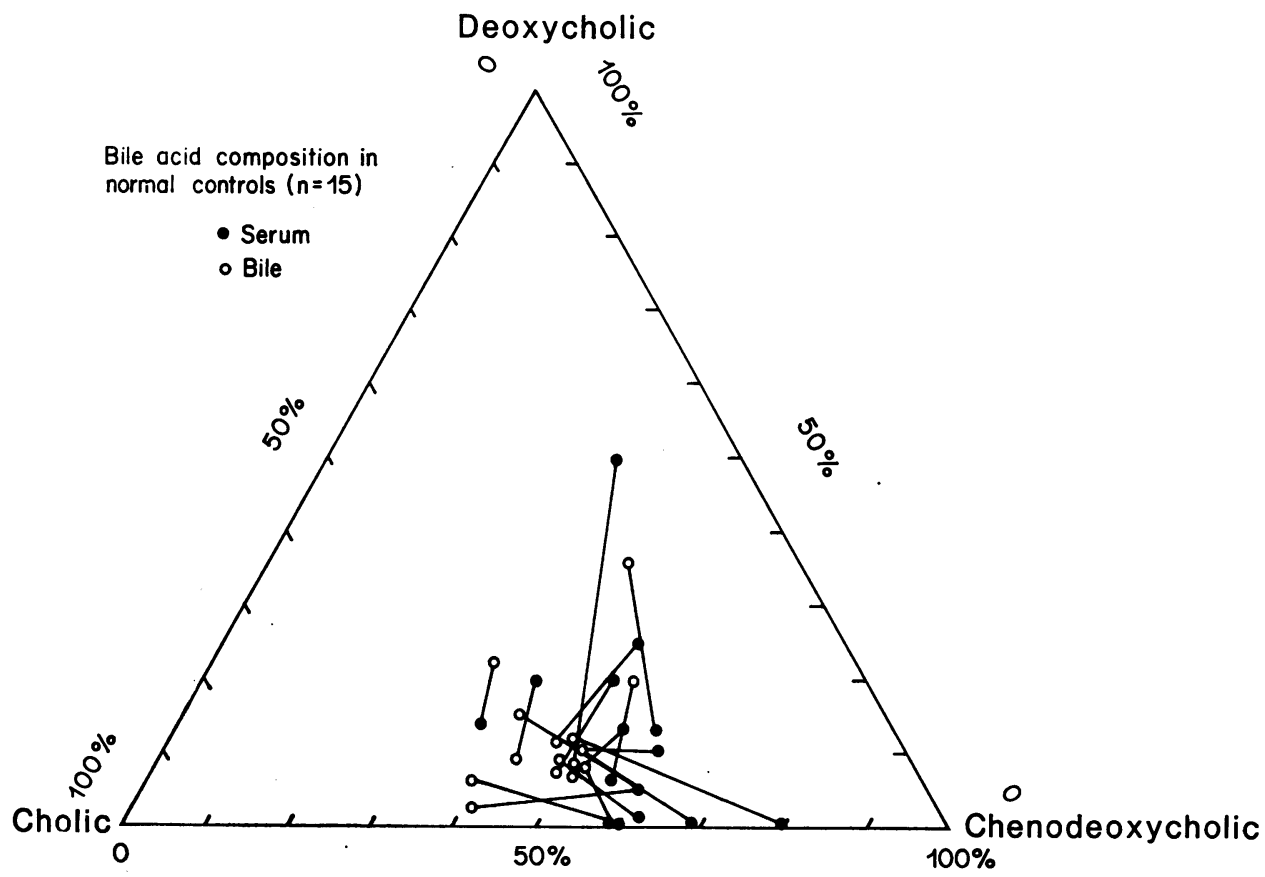

Fig. 7 Bile acid composition of fasting-state serum and bile (obtained by CKK stimulation) from healthy control subjects plotted as described in Fig. 6. The greater proportion of chenodeoxycholic acid in the serum sample is statistically significant.

0.82) as well as between total bile acids and alkaline phosphatase $(r=0.66)$. In patients with primary biliary cirrhosis, good correlation exists between SGOT and total serum bile acids $(r=0.72)$. There was a very high correlation between alkaline phosphatase and $5^{\prime}$-nucleotidase activities in all patients $(r=0.90)$.

\section{Discussion}

These data, which define the bile acid pattern of the sulphated and unsulphated fractions in serum, urine, and bile of patients with cholestasis, cirrhosis, and healthy controls, provide the first comprehensive description of the alterations in bile acid metabolism occurring in patients with obstructive hepatobiliary disease. The most important finding is the great increase in the formation of primary bile acid sulphates, especially chenodeoxycholic acid, which is associated with a striking increase in the excretion of bile acids in the urine. The site of bile acid sulphation is not known, but it can occur in the liver (Palmer, 1967; Liersch and Stiehl, 1974). A second predictable change is the virtual disappearance of secondary bile acids from serum, urine, and bile due to decreased passage of bile acids into the distal intestine, as first described by Sjövall (1960). A minor change is the appearance of the novel bile acid, hyocholic acid, which indicates increased 6hydroxylation. 6-Hydroxylation of bile acids has been reported in isolated subcellular fractions of human liver, but does not occur appreciably in healthy subjects (Trülzsch et al., 1974). Evidence that 6hydroxylation of bile acids in man occurs during cholestasis has recently been presented by Summerfield et al. (1976). The presence of other unusual bile acids like $3 \beta$-hydroxy-5-cholen-24-oic and ursodeoxycholic acid in urine of patients with cholestasis has been described by Makino et al. (1971) and Back (1973) and was confirmed in the present study.

Faecal bile acids were not measured in our subjects, but are thought to be quite low in patients with cholestasis (Miettinen, 1973). The average urinary excretion in our subjects with complete extrahepatic obstruction was $71.6 \mathrm{mg} /$ day, compared with published figures for daily bile acid synthesis of $250 \mathrm{mg} /$ day, based on chemical measurements of faecal bile acids in normal subjects eating a solid diet (Miettinen, 1973). If urinary bile acid excretion can be equated with bile acid synthesis, then synthesis appears to be diminished in patients with cholestasis. 
In the cirrhotic patient, the pattern of serum bile acids differed from that in cholestasis in containing relatively more chenodeoxycholic acid. Since bile acid kinetics were not carried out, we cannot define the mechanism responsible for this difference. A markedly reduced cholic acid synthesis, in cirrhosis, as shown by McCormick et al. (1973), could contribute.

Finally, in all patients it is clear that the bile acid pattern of serum, urine, and bile show consistent differences both in health and disease. This finding was first reported by Erb et al. (1972, 1973), and has now been confirmed independently by radioimmunoassay (Schalm et al., 1975). There is considerable evidence suggesting that chenodeoxycholic acid may be absorbed passively from the intestine (Hislop et al., 1967; Schiff ct al., 1972), and is cleared less efficiently by the liver (Cowen et al., 1975; Hoffman et al., 1975). Thus, bile always contains more cholic acid, and in serum, chenodeoxycholic acid is the dominant bile acid. The pattern of urinary bile acids reflects the product of the renal clearance of each individual bile acid and its average serum concentration. Thus, the dominant urinary bile acids are those with the highest clearance-namely, the bile acid sulphates.

\section{CLINICAL CORRELATIONS}

Our studies do not lend support to the proposal that the pattern of serum bile acids provides useful diagnostic information in the patient with cholestasis. In our patients, the presence of deoxycholic acid appeared to exclude the diagnosis of complete biliary obstruction, but it is doubtful if this association will prove to be clinically useful. The absence of deoxycholic acid does not provide useful diagnostic information, as it may reflect either decreased formation or decreased substrate availability. Thus, the data presented here support the suggestion of LaRusso et al. (1975) that the clinical value of serum bile acid measurements is likely to be greatest in patients with anicteric liver disease.

We are indebted to Dr A. F. Hofmann for many helpful suggestions in the preparation of this manuscript and for carrying out control determinations of serum bile acids with specific radioimmunoassays and to Miss A. T. Ruben for assistance in the bile acid analyses. This study was supported by grants from the Dutch Health Organisation TNO and 'de Drie Lichten'.

\section{References}

Admirand, W. H., Stiehl, A., and Thaler, M. M. (1972). Sulfation of bile salts: an important metabolic pathway in cholestasis (Abstract). Gastroenterology, 62, 190.
Back, P. (1973). Identification and quantitative determination of urinary bile acids excreted in cholestasis. Clinica Chimica Acta, 44, 199-207.

Carey, J. B., Jr (1958). The serum trihydroxy-dihydroxy bile acid ratio in liver and biliary tract disease. Journal of Clinical Investigation, 37, 1494-1503.

Cowen, A. E., Korman, M. G., Hofmann, A. F., and Thomas, P. J. (1975). Plasma disappearance of radioactivity after intravenous injection of labelled bile acids in man. Gastroenterology, 68, 1567-1573.

Erb, W., Schreiber, G., and Walczak, M. (1972). Gaschromatographische Untersuchungen der Serumgallensäuren: Methodik sowie Ergebnisse bei Patienten mit akuter Hepatitis. Zeitschrift für Gastroenterologie, 10, 349358.

Erb, W., Schreiber, G., and Walczak, M. (1973). Untersuchungen der Gallensäuren im Serum von Patienten mit Extrahepatischer Cholostase und mit Chronische Lebererkrankungen. Zeitschrift für Gastroenterologie, 11, 279-288.

Gregg, J. A. (1967). Presence of bile acids in jaundiced human urine. Nature, 214, 29-31.

Greim, H., Trülzsch, D., Czygan, P., Rudick, J., Hutterer, F., Schaffner, F., and Popper, H. (1972). Mechanism of cholestasis. 6. Bile acids in human livers with or without biliary obstruction. Gastroenterology, 63, 846-850.

Hislop, I. G., Hofmann, A. F., and Schoenfield, L. J. (1967). Determinants of the rate and site of bile acid absorption in man (Abstract). Journal of Clinical Investigation, 46, 1070.

Hoffman, N. E., Iser, J. H., and Smallwood, R. A. (1974). Hepatic bile acid transport: effect of conjugation and position of hydroxyl groups. American Journal of Physiology, 229, 298-302.

Hofmann, A. F., and Mosbach, E. H. (1964). Identification of allodeoxycholic acid as the major component of gallstones induced in the rabbit by $5 \alpha$-cholestan-3 $\beta$-ol. Journal of Biological Chemistry, 239, 2813-2821.

LaRusso, N. F., Hoffman, N. E., Hofmann, A. F., and Korman, M. G. (1975). Validity and sensitivity of an intravenous bile acid tolerance test in patients with liver disease. New England Journal of Medicine, 292, 1209-1214.

Liersch, M., and Stiehl, A. (1974). Bildung von Gallensäuresulfatester in perfundierten Rattenlebern nach Gallengangverschluss. Zeitschrift für Gastroenterologie, 12, 131-134.

McCormick, W. C. III, Bell, C. C. Jr, Swell, L., and Vlahcevic, Z. R. (1973). Cholic acid synthesis as an index of the severity of liver disease in man. Gut, 14, 895-902.

Makino, I., Hashimoto, H., Shinozaki, K., Yoshino, K., and Nakagawa, S. (1975). Sulphated and nonsulphated bile acids in urine, serum, and bile of patients with hepatobiliary diseases. Gastroenterology, 68, 545-553.

Makino, I., Nakagawa, S., and Mashimo, K. (1969). Conjugated and unconjugated serum bile acid levels in patients with hepatobiliary diseases. Gastroenterology, 56, 10331039.

Makino, I., and Sjövall, J. (1972). A versatile method for analysis of bile acids in plasma. Analytical Letters, 5, 341349.

Makino, I., Sjövall, J., Norman, A., and Strandvik, B. (1971). Excretion of $3 \beta$-hydroxy- $\Delta^{5}$-cholenoic and $3 \alpha$-hydroxy- $5 \alpha-$ cholanoic acids in urine of infants with biliary atresia. FEBS Letters, 15, 161-164.

Miettinen, T. A. (1973). Clinical implications of bile acid metabolism in man. In The Bile Acids, vol. 2, pp. 191-247. Edited by P. P. Nair and D. Kritchevsky. Plenum Press: New York-London.

Murphy, G. M., Ross, A., and Billing, B. H. (1972). Serum bile acids in primary biliary cirrhosis. Gut, 13, 201-206.

Palmer, R. H. (1967). The formation of bile acid sulfates: a 
new pathway of bile acid metabolism in humans. Proceedings of the National Academy of Sciences of the United States of America, 58, 1047-1050.

Palmer, R. H., and Bolt, M. G. (1971). Bile acid sulfates. I. Synthesis of lithocholic acid sulfates and their identification in human bile. Journal of Lipid Research, 12, 671-679.

Popper, H., and Schaffner, F. (1970). Non-suppurative destructive chronic cholangitis and chronic hepatitis. In Progress in Liver Disease, vol. 3, pp. 336-354. Edited by H. Popper and F. Schaffner. Grune and Stratton: New York.

Rudman, D., and Kendall, F. E. (1957). Bile acid content of human serum. I. Serum bile acids in patients with hepatic disease. Journal of Clinical Investigation, 36, 530-537.

Sandberg, D. M., Sjövall, J., Sjövall, K., and Turner, D. A. (1965). Measurement of human serum bile acids by gasliquid chromatography. Journal of Lipid Research, 6, 182192.

Schalm, S. W., Turcotte, J., Hofmann, A. F., and Cowen, A. E. (1975). A new bile acid radioimmunoassay: development, validation and preliminary application of an assay for chenodeoxycholyl conjugates (Abstract). Gastroenterology, 68, 913.

Scheuer, P. (1973). Liver biopsy interpretation. 2nd edn. Baillière, Tindall: London.

Schiff, E. R., Small, N. C., and Dietschy, J. M. (1972). Characterisation of the kinetics of the passive and active transport mechanisms for bile acid absorption in the small intestine and colon of the rat. Journal of Clinical Investiga- tion, 51, 1351-1362.

Simmonds, W. J., Korman, M. G., Go, V. L. W., and Hofmann, A. F. (1973). Radioimmunoassay of conjugated cholyl bile acids in serum. Gastroenterology, 65, 705-711. Sjövall, J. (1960). Bile acids in man under normal and pathological conditions. Bile acids and steroids 73. Clinica Chimica Acta, 5, 33-41.

Stiehl, A. (1974). Bile salt sulphates in cholestasis. European Journal of Clinical Investigation, 4, 59-63.

Stiehl, A., Earnest, D. L., and Admirand, W. H. (1975). Sulfation and renal excretion of bile salts in patients with cirrhosis of the liver. Gastroenterology, 68, 534-544.

Summerfield, J. A., Billing, B. H., and Shackleton, C. H. L. (1976). Identification of bile acids in the serum and urine in cholestasis. Biochemical Journal, 154, 507-516.

Trülzsch, D., Roboz, J., Greim, H., Czygan, P., Rudick, J., Hutterer, F., Schaffner, F., and Popper, H. (1974). Hydroxylation of taurolithocholate by isolated human liver microsomes. I. Identification of metabolic product. Biochemical Medicine, 9, 158-166.

Turnberg, L. A., and Grahame, G. (1970). Bile salt secretion in cirrhosis of the liver. Gut, 11, 126-133.

van Berge Henegouwen, G. P. (1974). Bile Acids and Cholestasis. Thesis, Nijmegen, The Netherlands.

van Berge Henegouwen, G. P., Ruben, A. T., and Brandt, K. H. (1974). Quantitative analysis of bile acids in serum and bile, using gas-liquid chromatography. Clinica Chimica Acta, 54, 249-261. 